\title{
Analisis Panel Data Web Scraping Artikel Kekerasan Dalam Rumah Tangga Tahun 2019- 2020 di DKI Jakarta
}

\author{
Tiara Dameani \\ BPS Provinsi Sulawesi Utara \\ dame.simamora@bps.go.id
}

\begin{abstract}
ABSTRAK
Kekerasan Dalam Rumah Tangga adalah tindak kejahatan oleh individu yang terjadi pada lingkup yang kecil dan oleh orang yang di kenal oleh korban. Pada penelitian ini data tindak Kekerasan dalam Rumah Tangga melalui data yang di peroleh dengan metode web scraping artikel di media online tahun 20192020 pada lima kota di Provinsi DKI Jakarta. Selain data scraping penelitian ini juga menggunakan dua sumber data tambahan (1) data Survei Sosial Ekonomi Nasional dalam mengukur tingkat konsumsi alkohol dan rata- rata harga alkohol pada kota-kota di jakarta. (2) Data publikasi resmi pada website Badan Pusat Statistik dalam mengukur tingkat pengangguran dan pengeluaran per kapita. Hasil dari penelitian ini (1) Mengambarkan bagaimana cara Scraping media online menggunakan aplikasi Kapow (2) Pemodelan data Panel Pooled Least square hubungan KDRT dengan lingkungan pada level kota. Kesimpulan dari penelitian ini (1)bahwa dengan metode web scraping peneliti dapat dengan mudah mendapat data dan lebih real time dibandingkan harus menunggu laporan resmi pengadilan, (2) konsumsi alkohol, harga, tingkat pengangguran, pengeluaran per kapita tidak mengidentifikasi berpengaruh terhadap tindak Kekerasan Dalam Rumah tangga, hal ini mungkin disebabkan oleh faktor psikologi dibandingkan dengan faktor lingkungan. Saran untuk penelitian selanjutnya lebih memperluas lagi faktor penyebab KDRT dan memperluas periode data panel yang tidak hanya terbatas pada dua periode saja.
\end{abstract}

Kata kunci : Web Scraping, Kapow, KDRT

\begin{abstract}
Domestic Violence is a crime by individuals that occurs in a small scope and by people known to the victim. In this study, data on Domestic Violence was obtained using the web scraping method for articles in online media for 2019-2020 in five cities in DKI Jakarta Province. In addition to scraping data, this study also uses two additional data sources (1) the National Socio-Economic Survey data in measuring the level of alcohol consumption and the average price of alcohol in cities in Jakarta. (2) Official publication data on the website of the Central Bureau of Statistics in measuring the unemployment rate and per capita expenditure. The results of this study (1) Describe how to scrap online media using the Kapow application (2) Modeling data panel Pooled Least Square relationship of domestic violence with the environment at the city level. The conclusions of this study are (1) that with the web scraping method researchers can easily get data and are more real time than having to wait for official court reports, (2) alcohol consumption, prices, unemployment rates, per capita expenditures do not identify an effect on Internal Violence. Bulk stairs, this may be caused by psychological factors rather than environmental factors. Suggestions for further research are to further expand the factors that cause domestic violence and expand the panel data period which is not only limited to two periods.
\end{abstract}

Keywords: Web Scraping, Kapow, KDRT 


\section{PENDAHULUAN}

Kemajuan teknologi memungkinkan penelitian untuk mendapatkan data terkini yang lebih cepat dan murah. Salah satu metode yang dapat digunakan untuk mengumpulkan data ialah dengan cara mengambil data di website. Salah satu caranya adalah dengan metode web scraping. Metode web scraping adalah personalisasi robot web yang diciptakan untuk membantu pengguna didasarkan ketertarikan pengguna kepada konten spesifik pada halaman web, mengekstraknya dan menyimpannya dalam sistem file maupun database untuk pemanggilan kembali ataupun analisis.[1]. Teknik ini memberikan pengguna cara mengumpulkan data secara otomatis pada website daring (online) dimana cara tersebut lebih efektif, efisien dan ekonomis dibandingkan cara yang digunakan secara tadisional [2]. Metode ini dapat dikatakan memberikan harapan besar untuk peneliti dalam mengumpulkan data di bidang tindak pidana hukum. Web scraping juga dapat digunakan sebagai alat untuk penelitian tindak kejahatan [3]. Salah satu situs penyedia informasi yang dapat dilakukan ekstraksi data (scraping) dan yang sangat sering dikunjungi adalah situs berita [4]. Pengambilan data melalui metode web scraping dalam penelitian ini dibatasi adalah artikel kekerasan dalam rumah tangga (KDRT) di media elektronik yang terjadi di Jakarta.

Menurut Catatan Tahunan Komnas Perempuan Tahun 2020 (CATAHU) setidaknya ada sebanyak 299,911 Kasus kekerasan terhadap perempuan selama tahun 2019 di Indonesia, Dimana menurut CATAHU Jakarta pada tahun 2020 adalah provinsi tertinggi kasus KDRT sebanyak 2,461 kasus kekerasan terhadap perempuan, itu hanya tercatat yang terjadi pada perempuan. Beberapa penelitian menunjukkan adanya hubungan positif perilaku konsumsi minuman keras terhadap tindak kekerasan seperti [5] mengatakan bahwa konsumsi alkohol memberikan sumbangsih sebesar $25 \%$ sampai $50 \%$ terjadinya kekerasan di lingkungan sekitar,
Penelitian sebelumnya menemukan bahwa penyalahgunaan alkohol berpengaruh signifikan dalam mempengaruhi kekerasan yang terjadi di rumah tangga [6]-[10]. Roizen (2002) merangkum beberapa kejahatan yang terjadi karena konsumsi alkohol sebagai berikut: (1) $86 \%$ pelaku pembunuhan, (2) $37 \%$ Pelaku kekerasan ,(3) $60 \%$ pelaku kekerasn seksual, dan (4) $13 \%$ pelaku kekerasan terhadap anak. Berbagai Perilaku kekerasan tersebut adalah dampak dari mengkonsumsi alkohol yang dapat merusak otak dan mengganggu baik secara fisik dan mental ( Barnes;2014). Markowitch: 2000 juga menemukan bahwa ada hubungan peningkatan harga alkohol terhadap penurunan tindak kekerasan pada lingkungan [11]. Dari beberapa penelitian tersebut dapat di katakan alkohol mempengaruhi perilaku individu dalam melakukan tindak kekerasan. Penelitian mengatakan akses pembelian alkohol yang semakin dekat berpengaruh positif terhadap terjadinya tindak kekerasan di lingkungan [12]-[15].

Dalam Kasus di Indonesia alkohol sangat mudah di dapat baik itu berupa minuman bermerek ataupun minuman daerah yang mengandung alkohol, untuk daerah yang memiliki tingkat konsumsi alkohol yang tinggi dapat mempengaruhi individu lain untuk ikut mengkonsumsi ataupun berperilaku yang sama, lingkungan mempengaruhi perilaku individu melalui proses pengamatan [16], hal ini lah yang mendorong peneliti melakukan penelitian dan untuk mendapat data yang real time peneliti menggunakan metode web scraping sehingga menulis artikel penelitian ini.

\section{METODE}

\subsection{Metode Web Scraping}

Pengambilan data jumlah KDRT hanya dilakukan pada satu situs berita saja untuk menghindari adanya duplikasi berita pada situs yang berbeda. Metode pengambilan data jumlah KDRT menggunakan metode web scraping pada situs detik.com. Pemilihan pada 
situs detik.com dikarenakan selain memiliki struktur halaman web yang lebih teratur dan cukup mudah untuk diekstrak datanya, juga merupakan salah satu website berita nasional yang cukup banyak diakses oleh penduduk Indonesia berdasarkan Alexa Traffic Rank (ATR).

Aplikasi yang digunakan untuk pelaksanaan scraping adalah aplikasi dari perusahaan Kofax yang bernama Kapow. Aplikasi ini menyediakan integrasi otomatis dari data terstruktur maupun tidak terstruktur dari berbagai sumber data seperti web interface, database, spreadsheet, aplikasi desktop dan lainnya. Dengan aplikasi Kapow ini, kita dapat membuat sebuah robot untuk mengautomasi dan mengintegrasikan pekerjaan manusia. Pemilihan aplikasi ini dikarenakan aplikasi ini cukup mudah digunakan untuk melakukan scraping dengan menjalankan suatu algoritma tertentu tanpa harus melakukan coding syntax. Aplikasi ini juga dapat digunakan secara penuh ( bukan trial) karena Badan Pusat Statistik (BPS) sudah memiliki ijin penggunaan aplikasi tersebut.

Kata pencarian untuk melakukan ekstraksi web data pada penelitian ini adalah 'Kekerasan Dalam Rumah Tangga'. Hasil ekstraksi data disortir sesuai tanggal rilis sejak tahun 2020 sampai dengan tahun 2019.

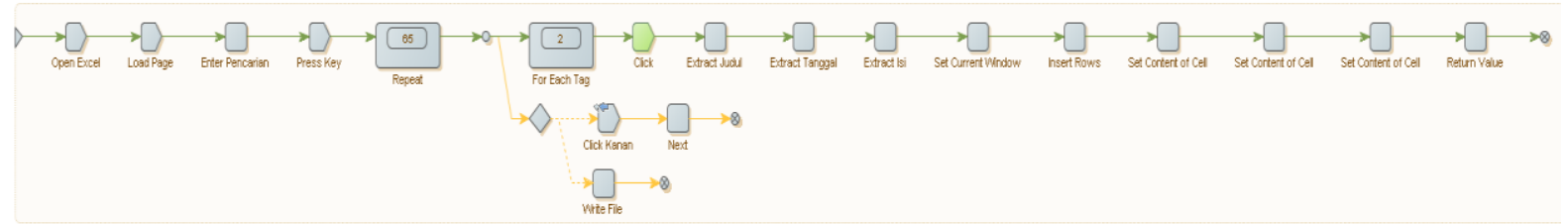

Gambar 1. Tampilan algoritma pada aplikasi Kapow

Adapun gambaran/Output hasil dari web scraping pada aplikasi Kapow terlihat seperti gambar 2 .

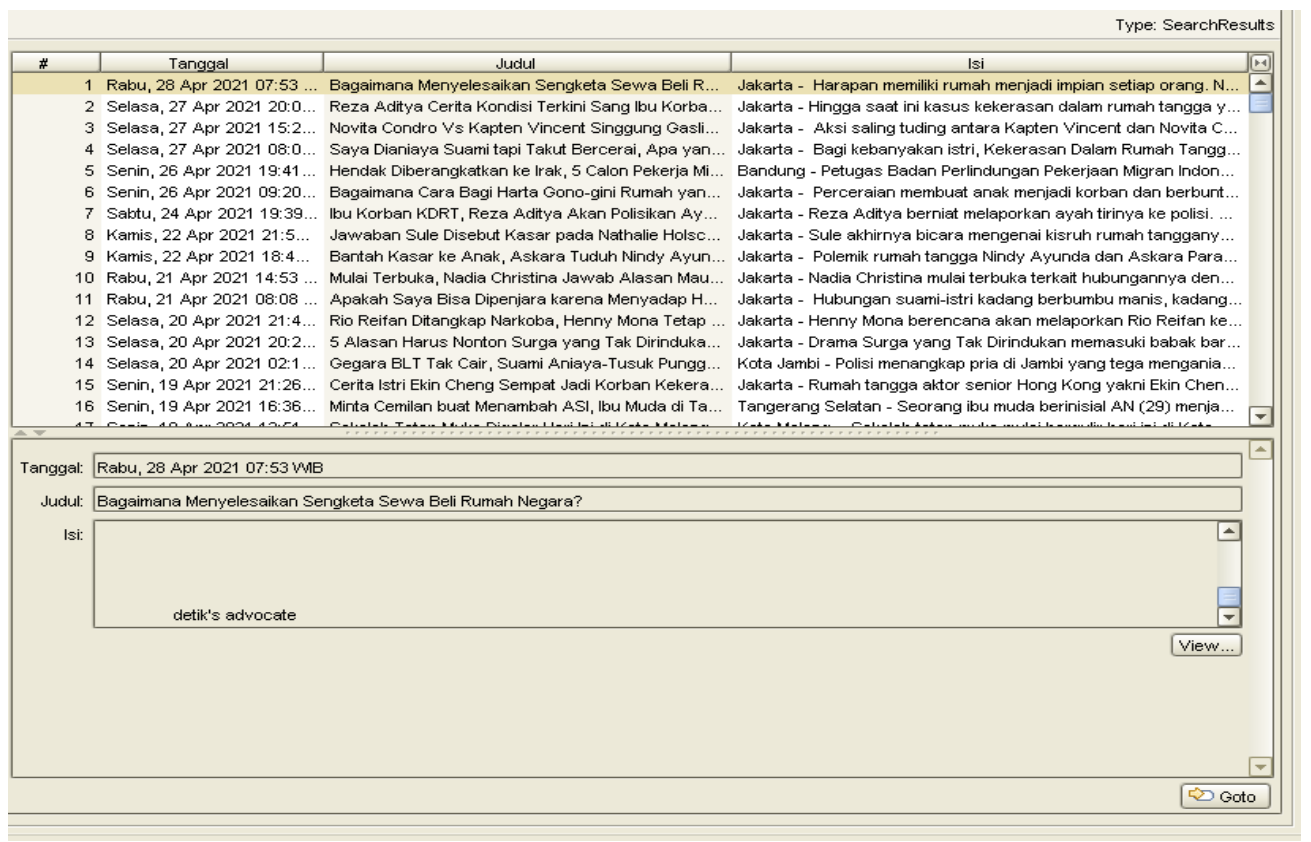

Gambar 2 tampilan output pada pada aplikasi Kapow

Hasil dari web scraping ini adalah data yang terstruktur berupa tabel dengan format excel (.CSV), terdiri dari tanggal terbit artikel, judul dan isi artikel seperti gambar 3. Hasil dari excel tersebut dilakukan sort dan filter hanya untuk artikel yang terjadi di wilayah Jakarta dan membahas kejadian terjadinya KDRT. 


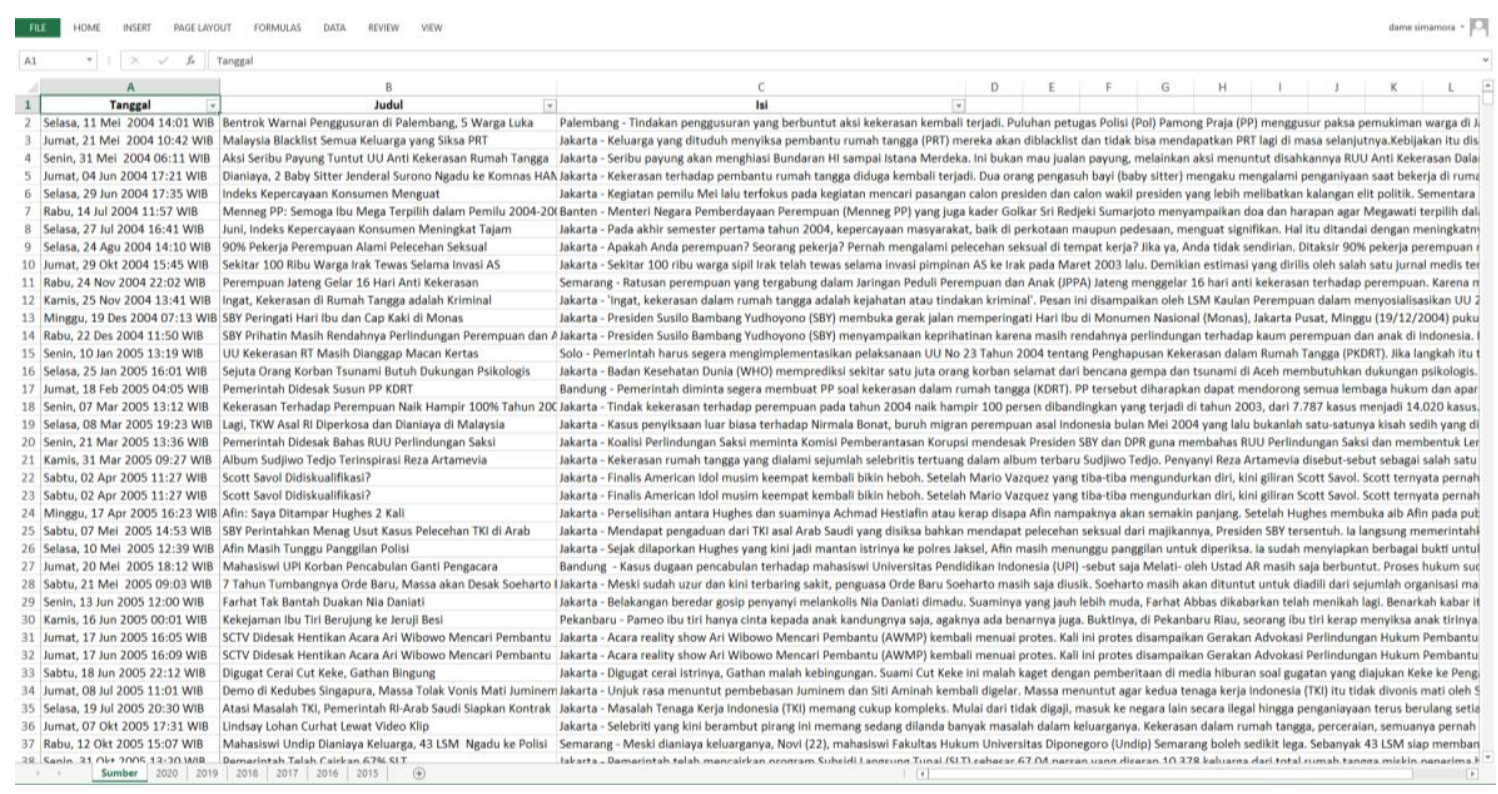

Gambar 3 tampilan hasil scraping pada excel (.CSV)

\subsection{Metode Empiris}

\subsubsection{Data}

Sampel dari penelitian ini adalah lima kota yang ada di provinsi DKI jakarta yaitu: Jakarta Utara, Jakarta Selatan, Jakarta Timur, Jakarta Barat dan Jakarta pusat. Data KDRT di peroleh pada media online https://www.detik.com tahun 2019 dan 2020, dimana data tersebut merupakan artikel berita yang diperoleh melalui metode web scraping dan kemudian di agregasi pada level kota.
Pengukuran data tingkat konsumsi alkohol dan tingkat harga ialah agregat dari konsumsi dan pembelian alkohol dalam rumah tangga pada kota di jakarta yang didapatkan dari data Survei Sosial Ekonomi Nasional, dan untuk data tingkat pengangguran dan pengeluaran per kapita adalah data publikasi resmi dari halaman web Badan Pusat Statistik.

\subsubsection{Metode}

Penelitian ini menggunakan data panel 2019 dan 2020 dengan level agregat kota faktor yang mempengaruhi KDRT dengan Model:

$$
Y i t=\alpha+\beta 1 X 1 i t+\beta 2 X 2 i t+\beta 3 X 3 i t+\beta 4 X 4 i t+e
$$

Dimana $\mathrm{Y}$ adalah kekerasan rumah tangga yang terjadi pada kota I dan tahun $\mathrm{t}, \mathrm{X} 1$ adalah tingkat konsumsi alkohol kota I pada tahun $\mathrm{t}, \mathrm{X} 2$ rata-rata harga alkohol kota I pada tahun $\mathrm{t}$, X3 tingkat penganguran kota I pada tahun $\mathrm{t}$ dan $\mathrm{X} 4$ adalah pengeluaran per kapita kota I pada tahun $\mathrm{t}$.

\section{Hasil dan Pembahasan}

Tabel 1 menunjukkan summary dari variabel dependen dan variabel kontrol dalam penelitian ini. Dalam penelitian ini menggunakan data tahun 2019 dan 2020, dimana variabel utama penelitian ini yaitu banyaknya jumlah artikel yang memuat berita kekerasan dalam rumah tangga yang di peroleh melalui metode web scraping pada lima kota di jakarta., diantaranya adalah Jakarta Timur, Jakarta Barat, Jakarta Utara, Jakarta Selatan dan Jakarta Pusat

Rata-rata artikel KDRT pada sampel ada sebanyak 5 artikel per kota dimana yang terendah ada 3 artikel dan tertinggi ada 15 artikel dalam satu kota. Konsumsi alkohol rata- 
rata individu per kota selama tahun 2019-2020 adalah sebesar 1,1 L dan terbesar sebesar $1.8 \mathrm{~L}$ dalam satu minggu. Harga rata-rata alkohol adalah sebesar RP. 33,737 per Liter dengan harga tertinggi Rp. 81,630 per Liter. Rata- rata persentase pengangguran terbuka sebesar
$8.71 \%$ dengan persentase terendah sebesar $5.21 \%$ dan tertinggi sebesar $12.27 \%$. Pengeluaran per kapita rata- rata selama setahun adalah sebesar Rp. 19,534.9 juta dengan nilai minimal sebesar Rp. 17.180 juta dan nilai tertinggi sebesar Rp. 23,851 juta.

Tabel 1

\begin{tabular}{|l|r|r|r|r|r|}
\hline \multicolumn{1}{|c|}{ Variable } & \multicolumn{1}{c|}{ Obs } & \multicolumn{1}{c|}{ Mean } & \multicolumn{1}{c|}{ Std. Dev. } & \multicolumn{1}{c|}{ Min } & \multicolumn{1}{c|}{ Max } \\
\hline & & & & & 15 \\
\hline Jumlah artikel KDRT & 10 & 5.9 & 3.84 & 3 & 1.8 \\
\hline Konsumsi Alkohol & 10 & 1.1 & 0.60 & 0 & 81,630 \\
\hline Harga & 10 & 33737.08 & 26315.09 & 0 & 12.27 \\
\hline $\begin{array}{l}\text { Pengangguran } \\
\text { Terbuka }\end{array}$ & 10 & 8.714 & 2.61 & 5.21 & 23,851 \\
\hline Pengeluaran Per Kapita & 10 & 19534.9 & 2545.22 & 17,180 & \\
\hline
\end{tabular}

Analisis

Tabel 2

\begin{tabular}{|c|c|c|c|c|}
\hline & kdrt & kdrt & kdrt & kdrt \\
\hline \multirow[t]{2}{*}{ alkohol } & -3.263 & -4.021 & -3.316 & -1.620 \\
\hline & $(-1.70)$ & $(-2.00)$ & $(-1.30)$ & $(-0.72)$ \\
\hline \multirow[t]{2}{*}{ harga } & & 0.005 & 0.004 & -0.001 \\
\hline & & (1.12) & $(0.80)$ & $(-0.12)$ \\
\hline \multirow[t]{2}{*}{ Penganguran } & & & 0.280 & 0.554 \\
\hline & & & $(0.49)$ & (1.15) \\
\hline \multirow[t]{2}{*}{ pengeluaran } & & & & 0.001 \\
\hline & & & & (2.02) \\
\hline \multirow[t]{2}{*}{ _cons } & $9.535^{* *}$ & $8.625^{*}$ & 5.730 & -14.589 \\
\hline & (3.96) & (3.44) & $(0.89)$ & $(-1.29)$ \\
\hline $\mathrm{N}$ & 10 & 10 & 10 & 10 \\
\hline
\end{tabular}

t statistics in parentheses

$=" * p<0.05 \quad * * p<0.01 \quad * * * p<0.001 "$

Dari hasil analisis data panel dengan menggunakan model pooled least square keempat variabel penjelas penelitian ini yaitu, konsumsi alkohol, harga, tingkat pengangguran dan pengeluaran per kapita kota di Jakarta tidak memberikan adanya hasil yang signifikan, hal ini menunjukkan adanya faktor lain yang menyebabkan terjadinya 
kekerasan dalam rumah tangga yang mungkin disebabkan oleh faktor psikologis, namun setidaknya tujuan dari penelitian ini

\section{Kesimpulan dan Saran}

Metode web scraping memudahkan peneliti mendapat data dengan lebih cepat dan mudah didamping terdapat beberapa kelemahan dalam metode web scraping pada media elektronik yaitu tidak semua tindak KDRT termuat dalam media tersebut. Dari hasil analisis statistik yang dilakukan juga belum dapat menjelaskan bahwa konsumsi alkohol,

\section{REFERENCES}

[1] B. Amil et al., “No 主観的健康感を中 心とした在宅高齢者における健康 関連指標に関する共分散構造分析 Title," J. Chem. Inf. Model., vol. 21, no. 1, pp. 1-9, 2020, [Online]. Available: https://doi.org/10.1016/j.tmaid.2020. 101607\%0Ahttps://doi.org/10.1016/j.ij su.2020.02.034\%0Ahttps://onlinelibrar y.wiley.com/doi/abs/10.1111/cjag.122 28\%0Ahttps://doi.org/10.1016/j.ssci.2 020.104773\%0Ahttps://doi.org/10.101 6/j.jinf.2020.04.011\%0Ahttps://doi.o.

[2] T. Karthikeyan, K. Sekaran, D. Ranjith, V. Vinoth kumar, and J. M. Balajee, "Personalized content extraction and text classification using effective web scraping techniques," Int. J. Web Portals, vol. 11, no. 2, pp. 41-52, 2019, doi: 10.4018/IJWP.2019070103.

[3] R. A. Irizarry, "Web scraping," Introd. to Data Sci., pp. 407-414, 2020, doi: 10.1201/9780429341830-23.

[4] A. co. Company, "Alexa Traffic Rank (ATR)," 2021. https://www.alexa.com/siteinfo.

[5] L. T. W. Liana and L. L. ADOLF, "Penyalahgunaan Konsumsi Alkohol Pada Minuman Keras Bagi Remaja Terhadap Kesehatan," 2019, doi: 10.31219/osf.io/2j795. memperlihatkan bahwa dengan metode web scraping peneliti bisa mendapat data terbaru dengan cepat dan mudah.

harga, tingkat pengangsuran dan pengeluaran per kapita berpengaruh terhadap KDRT dalam rumah tangga, sehingga untuk penelitian selanjutnya mungkin dapat dicari faktor lain yang mempengaruhi terjadinya KDRT mungkin faktor kesehatan mental ataupun tingkat kenyamanan pada lingkungan tempat tinggal dan untuk hasil yang lebih baik dengan memperbesar periode tahun penelitian.

[6] E. Rodriguez, K. E. Lasch, P. Chandra, and J. Lee, "Family violence, employment status, welfare benefits, and alcohol drinking in the United States: What is the relation?," J. Epidemiol. Community Health, vol. 55, no. 3, pp. 172-178, 2001, doi: 10.1136/jech.55.3.172.

[7] M. Livingston, S. Matthews, M. J. Barratt, B. Lloyd, and R. Room, "Diverging trends in alcohol consumption and alcohol-related harm in Victoria," Aust. N. Z. J. Public Health, vol. 34, no. 4, pp. 368-373, 2010, doi: 10.1111/j.1753-6405.2010.00568.x.

[8] J. Roizen, "Related Violence," vol. 13, pp. 7-40.

[9] K. C. Klostermann and W. Fals-Stewart, "Intimate partner violence and alcohol use: Exploring the role of drinking in partner violence and its implications for intervention," Aggress. Violent Behav., vol. 11, no. 6, pp. 587-597, 2006, doi: 10.1016/j.avb.2005.08.008.

[10] P. C. McKenry, T. W. Julian, and S. M. Gavazzi, "Toward a Biopsychosocial Model of Domestic Violence," J. Marriage Fam., vol. 57, no. 2, p. 307, 1995, doi: $10.2307 / 353685$.

[11] S. Markowitz, "The Price of Alcohol, Wife Abuse, and Husband Abuse," South. Econ. J., vol. 67, no. 2, p. 279, 
2000, doi: 10.2307/1061471.

[12] M. Livingston, "A longitudinal analysis of alcohol outlet density and domestic violence," Addiction, vol. 106, no. 5, pp. 919-925, 2011, doi: 10.1111/j.1360-0443.2010.03333.x.

[13] L. Zhu, D. M. Gorman, and S. Horel, "Alcohol outlet density and violence: A geospatial analysis," Alcohol Alcohol., vol. 39, no. 4, pp. 369-375, 2004, doi: 10.1093/alcalc/agh062.

[14] R. Laranjeira and D. Hinkly, "Avaliação da densidade de pontos de vendas de álcool e sua relação com a violência," Rev. Saude Publica, vol. 36, no. 4, pp.
455-461, 2002, doi: 10.1590/S003489102002000400011.

[15] H. R. Britt, B. P. Carlin, T. L. Toomey, and A. C. Wagenaar, "Neighborhood level spatial analysis of the relationship between alcohol outlet density and criminal violence," Environ. Ecol. Stat., vol. 12 , no. 4, pp. 411-426, 2005, doi: 10.1007/s10651-005-1518-3.

[16] Albert Bandura, "Social Cognitive Theory of Mass Communication," Media Psychol., vol. Volume 3(3, no. 3, pp. 265-299, 2001, doi: https://doi.org/10.1207/S1532785XME P0303_03. 